\title{
ENTREVISTA COM ANDRÉ PARENTE
}

Durante o XII Encontro Nacional da ABRAPSO, realizado em Outubro de 2003 em Porto Alegre, conversamos com André Parente. Participaram da conversa Virgínia Kastrup e Cleci Maraschin.

André Parente é doutor em cinema pela Universidade de Paris VIII, onde estudou (82-87) sob a orientação de Gilles Deleuze. Em 1987 torna-se professor da UFRJ, onde funda o Núcleo de Tecnologia da Imagem (N-imagem). Entre 1977 e 2003 realiza inúmeros filmes, vídeos e instalações onde predominam a experimentação. Entre os seus principais livros, estão : Yasujiro Ozu: o extraordinário cineasta do cotidiano ( Marco Zero, 1990); Imagem-máquina. A era das tecnologias do virtual (Ed. 34, 1993); Sobre o cinema do simulacro (Pazulin, 1998); O virtual e o hipertextual (Pazulin, 1999); Narrativa e modernidade : os cinemas não-narrativo do pós-guerra (Papirus, 2000), Redes Sensoriais: Arte, Ciência e Tecnologia (Contra-Capa, 2003), Tramas da rede (Sulinas, 2004, no prelo).

Cleci: André, você poderia iniciar nos contando um pouco de seu trabalho, de sua pes quisa atual.

André: Eu venho trabalhando nesses últimos cinco anos na criação e no desenvolvimento de um sistema de realidade virtual chamado Visorama. Trata-se de um sistema de visualização com aplicação na representação e na simulação dos espaços urbanos. Uma de suas aplicações poderia se na área do turismo histórico. A partir de um lugar turístico como o Corcovado ou o Pão de Açúcar, você pode ver a paisagem do Rio em vários momentos do tempo, ver como ela evoluiu, contar história desta paisagem. É um sistema totalmente original, tanto para o hardware, como para o software. O projeto é fruto de uma parceria do Núcleo de Cultura e Tecnologia da Imagem da Escola de Comunicação da UFRJ com um grupo de computação gráfica do Instituto de Matemática Pura e Aplicada (IMPA-CNPQ). Pelas especificidades desse sistema acabei desenvolvendo uma pesquisa teórica em relação às imagens panorâmicas e os ambientes imersivos. Tem sido para mim uma histó ria de muitas descobertas. Descobri que o primeiro panorama, que é um sistema completamente imersivo, foi criado em 1787, por um escocês, chamado Robert Barker, dois anos antes do panóptico. O sistema de Barker, na verdade, influenciou a criação do panóptico porque é um sistema arquitetônico imersivo, no qual o espectador fica no centro de uma plataforma, olhando pra uma imagem em torno, que tem 360 graus. Toda a idéia do dispositivo é de criar uma tal ilusão no espectador que ele olha para a imagem não como uma imagem, mas como se ela fosse uma realidade completa: a idéia é fazer o espectador se sentir em meio a realidade que o dispositivo simula. Esse é o primeiro sistema de tele-presença. O primeiro panorama apresentado em Londres - em Lecester Square mostrava uma vista da baía de Edinburgo: a idéia era fazer o espectador vivenciar a sensação de que, embora estando em Londres, se sentisse como se estivesse em Edimburgo. Nosso sistema tem muito a ver com isso, digamos, ele pertence a essa linhagem tecnológica na medida em que a arquitetura do nosso dispositivo tem, como base, imagens panorâmicas virtuais de 360 graus.

Cleci: É também um sistema interativo?

André: E, é um sistema ao mesmo tempo imersivo e interativo. É também um sistema hipertextual, porque trabalha com links no espaço que permitem o espectador saltar de um ponto a outro: estou de fato no Corcovado, vendo a paisagem circundante, mas posso pular para o Pão de Açúcar e ver a paisagem ao entorno, como se eu estivesse lá mesmo. $\mathrm{O}$ sistema simula um dispositivo óptico, um telescópio, um binóculo: a idéia é fazer o espectador ter a impressão que ele está olhando através da ocular, embora o que ele esteja vendo é uma imagem gerada pelo computador. Você cria uma estrutura de navegação que, por exemplo, permite ao espectador se deslocar no espaço (do Corcovado ao Pão de Açúcar) e no tempo (como a paisagem vista de um mesmo ponto mudou ao longo do tempo).

Cleci: Mudar a perspectiva?

André: Mudar a perspectiva e olhar a paisagem como se estivesse no Pão de Açúcar, vendo de lá, o espaço em torno, porque você pode girar 360 graus, e olhar a paisagem como se você estivesse girando com uma luneta na mão, um binóculo na mão.

Cleci: E além da produção de imagens é possível obter informações sobre o que vemos? Informações históricas?

André: Sim, a primeira aplicação para esse sistema, aquela que surgiu de imediato na cabeça da gente, foi a de uma aplicação nesta área de turis- 
Entrevista com André Parente

mo histórico, por uma razão até muito simples. Estamos no Rio de Janeiro, e o Rio de Janeiro possui o maior conjunto histórico, arquitetônico da América do Sul. Existem cidades como Ouro Preto, que tem um conjunto histórico arquitetônico muito importante, mas que possuem um único extrato histórico, enquanto que o Rio de Janeiro você tem coisas muito importantes de vários extratos históricos. Essa diversidade foi uma das características que nos levou a pensar na estrutura de navegação, para, por exemplo, possibilitar que espectador pudesse escolher a época que deseja navegar. Tratase de um dispositivo óptico que permite um deslocamento no espaço e no tempo. No espaço, porque existem vários pontos disponíveis para visualização e no tempo porque, para cada ponto, há a possibilidade de criar vários cortes temporais. Pode-se visitar o Rio pré-histórico, ou seja, num momento em que na paisagem não era percebida nenhuma intervenção humana e, a partir daí, visitar outros momentos que você achar que são importantes. No nosso caso, por exemplo, uma vez o sistema foi mostrado como uma instalação lá no MAM (Museu de Arte Moderna do Rio de Janeiro), numa exposição chamada "Paisagem Carioca" (2000). Tínhamos programado três momentos: a paisagem pré-histórica, a paisagem na passagem do século XIX para o século XX, que é quando a cidade se tornou uma cidade moderna e a paisagem atual. Em meu livro intitulado "O virtual e o hipertextual" existe uma fotografia do protótipo do Visorama e também uma série de ilustrações dos panoramas, para quem se interessar sobre estes sistemas de visualização imersivos.

Cleci: Como sua pesquisa evidencia, as experiências de tele-presença não são somente tributárias da informática, existem outros dispositivos que criam essa sensação. Mas qual a diferença em produzir esses efeitos com as novas tecnologias da informação e da comunicação?

André: Do ponto de vista da arte é possível fazer uma conexão do Visorama com questões epistemológicas da história da arte, que são muito interessantes, não apenas em função dos panoramas. Os panoramas são dispositivos que evoluíram no tempo e que geraram vários outros dispositivos, por exemplo, os cinemas, os parques temáticos, a própria realidade virtual. Ele já era um dispositivo de tele-presença, também podemos conecta-lo com esta idéia, que é bastante atual na arte, que são as instalações. Por quê? Porque o panorama representa, na história da arte um segundo processo de espacialização da imagem. O primeiro foi a pers- pectiva. A perspectiva produziu um corte epistemológico ao nível de um processo de representação da imagem. O panorama produz um outro do ponto de vista físico, porque é o espectador que está dentro do panorama, quer dizer, ele está imerso dentro do ambiente. O panorama ele não é apenas uma imagem, ele é antes um ambiente cognitivo - é claro que a pintura também é, mas apenas conceitualmente, do que propriamente do ponto de vista sensorial mesmo falando.

Cleci: Talvez essa seja uma questão interessante, a diferença vivencial e não somente conceitual..

André: Essa questão é uma das mais importantes. Existe um livro que a Virgínia conhece, que se chama "The techniques of the observer", de Jonathan Crary, no qual o autor discute uma série de mudanças operadas no início do século XIX por dispositivos imagéticos, entre eles o panorama ocupa um lugar muito importante. Ele descreve uma ruptura epistemológica ao nível da percepção, que mostra que a imagem, a partir de um determinado momento, começou a ser produzida para ser percebida pelo corpo inteiro. Trata-se de uma imagemsensação e não somente de uma imagem feita para ser percebida pelo olho da razão ou do espírito, que era, digamos assim, o que predominou na arte desde Platão até à Renascença. A Renascença conseguiu equacionar uma certa censura platônica em relação à representação do sensível, por quê? Porque criava um processo de isomorfia entre o que era usado para modelar a imagem e o que era usado para explicar aquilo que a imagem representava. O uso da geometria servia, ao mesmo tempo, para explicar a natureza e para construir uma imagem que representava essa natureza. Isso liberou os artistas da Renascença para criarem imagens que também tinham um lado sensível e não apenas alguma coisa que era da ordem do inteligível. Essa mesma ruptura que Crary aponta no início do século XIX foi de alguma forma antevista por filósofos como Diderot. Para Diderot, no final do século XVIII, a visitação de uma pintura de Chardin, mas também os de Gueuze e David, deveria ser acompanhada de uma luneta, por quê? Porque, dizia ele, quando vocês olharem o quadro de Chardin com a luneta, vocês vão ser transportados para dentro do universo que o quadro representa. Para esse tipo de quadro, esse tipo de estética, que eu hoje estou chamando de estética da transparência, Diderot já sabia situá-la perfeitamente. Ele tinha explicava da seguinte forma o modernismo emergente: a arte moderna só tem dois caminhos para evitar a teatralidade da imagem (que na ver- 
dade já era uma crítica que ele estava fazendo ao neoplatonismo que ainda persistia na pintura). Ou você cria uma imagem que vai valer como imagem e vai manter o espectador a distância, vai criar um processo de distanciamento em relação ao espectador; ou você cria uma imagem que vai trazer o espectador para dentro da imagem. Esses dois caminhos criam duas estéticas: a estética da opacidade e a estética da transparência. Nos dois casos, pouco importa se você escolhe uma via ou outra, a imagem vai estar atribuindo um lugar para o espectador. Neste caso, o espectador não é mais apenas o espectador como sujeito do conhecimento, sujeito que vê a imagem com os olhos do espírito da razão, que seria um sujeito, digamos, ainda da arte neoplatônica, mas já seria um sujeito carna mesmo, um sujeito que olha com o olho do sensível. Se pensarmos na história da pintura, a Olímpia de Manet foi o escândalo que inaugurou a arte moderna e abriu a via da estética da opacidade de uma maneira muito clara. O panorama seria a outra via, que é a da estética da transparência. Uma obra - ou uma imagem - não é pré-determinada, acabada, em relação ao espectador. Se na arte moderna a obra atribui um lugar para o espectador, no caso da arte contemporânea há uma interação entre o espectador e a obra de tal forma que a obra e o espectador só vão existir a partir da relação que se estabelece. As primeiras instalações que surgiram no Brasil com o neoconcretismo, como por exemplo os penetráveis do Hélio - podemos dizer que os brasileiros iniciaram essa espacialização da imagem ainda usando a pintura, dois ou três anos antes dos artistas minimalistas. Nós fomos um dos pioneiros da instalação, dessa nova forma de arte e dessa nova forma de espacialização da imagem que pede a participação do espectador, supõe uma interatividade, uma interatividade que no final dos anos 50 nada tinha a ver com a tecnologia.

Cleci: A estética da transparência não ajudaria a repensar o próprio conceito de repre sentação?

André: Certamente, a passagem do moderno ao contemporâneo e o surgimento da participação, da interação, rompe com a noção de representação. Você não pode sequer afirmar a existência de uma obra anterior à relação com o espectador, nem mesmo pode de falar de um espectador antes do encontro, já que ambos surgem daí. Podemos pensar isso na própria literatura. Borges cansou de dizer que o livro não existe se você não o lê, ou também que uma literatura difere de outra menos pelo seu conteúdo do que pela maneira como ela é lida. Tudo isso já é essa idéia muito contemporânea de que obra e espectador, ou observador nascem do encontro e supõem a participação.

Virgínia: Acho que é interessante a genealogia que tu produzes na tua fala, onde mostras que as coisas que a gente vive atualmente, algumas relações, têm sua origem muito antes das tecnologias, é um resgate bem interessante.

André: Bom, isso prova que eu aprendi bem com a Virgínia. O livro A invenção de si e do mundo é exatamente isso, o encontro inventa um si-mesmo (espectador) e um mundo (obra).

Virgínia: O Crary tem uma influência de Foucault, não?

André: É, bastante, ele diz isto abertamente..

Virgínia: A produção do percebedor e a produção do saber para as teorias da percepção e para as teorias da cognição vêm do mesmo fundo, isso é muito legal.

André: Do percebedor, ou seja, de um sujeito verdadeiramente estético, sensível, cuja experiência é valorizada, e não apenas um sujeito do conhecimento. E também a questão da produção do novo, que a gente poderia falar em termos de produção de subjetividade. Sei que o novo é uma palavra desgastada. O fato é que não há programação possível para essa experiência no sentido de prever o que vai acontecer.

Cleci: Só posteriormente podemos encontrar algumas das possíveis razões ...

André: Só a posteriori, exatamente. Isso se constitui um dos temores de alguns filósofos, com os quais eu concordo, que falam da possibilidade aberta pelas tecnologias de programação do real, de previsão e de predição. Como Lyotard denuncia que a arte da programação, a programação do aquiagora pode destruir o sentimento estético, a passibilidade estética, que é o solo do sentimento estético.

Cleci: Por que poderia tudo ser previamente antecipado?

André: Eu acho que você não é possível amarra as coisas dessa maneira, nem com tecnologia, nem com a arte. Nem a tecnologia, nem a arte podem programar no sentido de aprisionar ou liberar. Penso que é um erro atribuir à tecnologia e à arte, seja ela contemporânea ou não, a fabricação de um sujeito novo.

Virgínia: Essa questão que o André levanta é muito interessante, a questão da não oposição entre arte e tecnologia, quer dizer, não há nenhuma garantia....

André: Nem do controle, nem também da emanci- 
Entrevista com André Parente

pação.

Virgínia: Exatamente, nem a promessa de liberdade nem o determinismo do controle, mas com que arte, que tecnologia e qual o tipo de agenciamento que você estabelece.

André: Exatamente, que vai se estabelecer....

Virgínia: Como agenciamento, não há previsão nem de produção de liberdade, nem mesmo de controle. A discussão das relações entre tecnologia, sociedade, subjetividade, geralmente se dividem, como você falou, nessas duas posições, ou em um pessimismo, ou em um ufanismo. Penso que a posição interessante poderia ser essa de poder ver que a tecnologia não dita tudo anteriormente, nem também é inócua, ela produz. A tecnologia produz certamente, mas não de um modo determinístico, como um ambientalismo.

André: Uma certa configuração de agenciamento artístico e tecnológico que, em um momento pode gerar novas subjetividades, em outro pode constituir-se em um empecilho para criação. Tomemos o exemplo da fotografia. Em sua origem havia a idéia de se produzir imagens com as mesmas funções, digamos estéticas, que a pintura. Então foi preciso que a fotografia fosse descoberta pelos fotógrafos...que a inventaram esteticamente.

Cleci: O início do cinema também tinha a concepção do teatro ...

André: Exatamente, o cinema no início imitava o teatro, e pouco a pouco foi se descobrindo como cinema. Liberando-se dos modelos que o precederam. Na história da arte encontramos isso o tempo todo. Por exemplo, hoje estamos vivendo coisas novas em relação ao audiovisual, nestas experiências que vem sendo chamadas de novas mídias. Está ocorrendo um agenciamento muito forte da arte, do audiovisual, das tecnologias interativas, para criar instalações, que são consideradas instalações da "new mídia", ou da "arte mídia".

Cleci: Tal como o trabalho de Eduardo Kac? André: Eduardo Kac entre outros. Vemos surgir trabalhos que fazem convergir os campos da arte, do audiovisual e das campo das novas tecnologias (interfaces interativas). Para diferenciar das produções anteriores, as pessoas adotam o termo convergência. Mas se você pensar em relação ao passado, aconteciam também muitas convergências. Por exemplo, o cinema na sua forma tradicional e hegemônica, consiste em uma sala de exibição, que foi herdada do teatro italiano, com sua arquitetura específica. Os filmes são geralmente narrativos, e no mais das vezes esta narrativa possui uma forma que remete ao romance do século XIX, e junto a isso, também temos a tecnologia do cinema, que é a câmera e o projetor. Hoje assistimos a um renascimento do cinema por meio da espacialização da imagem, ou seja, outras arquiteturas estão emergindo, que vão criar novas relações com o espectador. O audiovisual e as novas tecnologias da imagem estão participando da renovação das artes plásticas através de instalações. A instalação permite ao artista espacializar os elementos constitutivos da obra. O termo indica um tipo de criação que recusa a redução da arte a um objeto para melhor considerar a relação entre seus elementos, entre os quais está o próprio espectador. A experiência da obra pelo espectador constitui um processo: sua percepção se efetua na duração de um percurso. Engajado em um percurso, implicado em um dispositivo, imerso em um ambiente, o espectador participa da mobilidade e mutabilidade da obra. O dispositivo designa a forma como a apresentação material da obra se inscreve em uma visada sistêmica, mas também o dispositivo de projeção que passou a constituir um elemento constitutivo das obras. A participação do espectador, por meio do uso de novas tecnologias, vem, pouco a pouco, ganhando maior amplitude. Neste caso, não apenas o espectador habita a obra, como pode com ela interagir, transformando-a com a sua ação.

Cleci: A questão da novidade é interessante. Michel Serres fala que a novidade das tecnologias consiste muito mais em um novo arranjo dos componentes do que propriamente uma novidade do objeto em si. Uma outra estruturação de elementos que emergiram em diferentes momentos históricos e que o momento atual torna possível o aparecimento de novas configurações.

André: Exatamente. Sobretudo ele fala da multitemporalidade, ele deixa bem claro que temos sempre muitos extratos, que vão convergir, mas os rearranjos e os agenciamentos desses extratos vão criar coisas diferentes a cada vez, isso é uma coisa super importante.

Cleci: E pra finalizar gostaria que tu comentasses um pouco essa sua passagem da psicologia para a comunicação...

André: Eu terminei o meu curso de Psicologia com uma monografia sobre a imagem, sobre a questão da percepção e da sensação. Tratava de historiar as diversas concepções da sensação e da percepção em relação à questão da produção da imagem. Virgínia: Você já fazia cinema na época?

André: Sim. Ao mesmo tempo que fiz esse trabalho teórico eu fazia filmes de curta-metragem, eu 
me engajei em movimentos de cinema independente e experimentais.

Virgínia: Isso ainda durante graduação em Psicologia?

André: Desde a graduação, ao concluir esse trabalho tive muita vontade de passar a estudar o cinema, pensar a questão do cinema de um ponto de vista teórico. Quando fui pra França eu tinha a idéia de trabalhar sobre uma falsa oposição entre imagem e narração, ou imagem e narrativa, assim como era falsa a oposição na pintura entre pintura abstrata e figurativa. Toda pintura é abstrata. O fato de uma pintura conter figuras não faz dela uma representação apenas. Isso também vale para o cinema, não é porque o filme conta uma história que ele é necessariamente parte de uma estética da representação. Tentei mostrar isso em minha tese que eu fiz com Deleuze em Paris. Trata-se inclusive de uma crítica Deleuziana do próprio Deleuze, porque ele ainda mantém a oposição entre imagem e narrativa. Tento mostrar que não é a imagem que se opõe a narrativa, mas são duas concepções da imagem, duas concepções da narrativa, uma da representação e outra como acontecimento. Para sustentar essa idéia tomei emprestado a concepção de Blanchot sobre a narrativa como acontecimento. Na verdade, não apenas Blanchot influenciou muito Deleuze e Foucault, como esta concepção dele da narrativa se aproxima dessa outra dimensão da linguagem (o sentido, o exprimível) que Deleuze destaca em seu livro "A Lógica do Sentido" (1969). Em toda a obra de Deleuze esta noção de sentido vai ser confrontada a estas outras dimensões que fazem da linguagem representação: significação, designação, enunciação.

A partir do cinema eu comecei a trabalhar com de realidade virtual. Concebi um sistema completo original, intitulado Visorama. No início a minha intenção era criar um sistema de realidade virtual que, ao contrário da maior parte dos sistemas de realidade virtual, não é utilizado para aperfeiçoar os esquemas sensórios-motores. Ao contrário, tratava-se de criar um sistema em que podia ser usado para fazer com que as pessoas pudessem romper com seus esquemas sensório-motores.

Cleci: Uma espécie de desnaturalização do olhar?

André: Sim, já estamos tão habituados a andar e a passar por lugares que não vemos mais. Não paramos de carregar essas imagens petrificadas, esses muros internos, com isso a gente deixa de ver o real enquanto novo. É preciso que um dia os nossos esquemas psicológicos se fragilizem para que a gente possa ver o real como se a gente tivesse vendo pela primeira. Essa inspiração me veio a partir de um sistema de realidade virtual criado por uma arquiteta que do ponto de vista da tecnologia não tem nada a ver com o meu, mas que me inspirou, em primeiro lugar teoricamente e depois na prática. É uma artista alemã chamada Mônica Flaschman, que criou um sistema chamado Berlin Cyber City. Sua idéia era que as pessoas já estão tão condicionadas pelo muro de Berlin, que mesmo o muro tendo desaparecido elas continuam a carregá-lo como tantas imagens petrificadas. Sua idéia foi de confrontar o espaço de Berlim, com e sem muro, para levar as pessoas a dissolver esse muro que elas carregam em si.

Cleci: Existem muitos projetos educativos que utilizam a tecnologia e que reforçam a idéia de tecnologizar as práticas já vividas e naturalizadas. Como se fossemos modelizar toda a historinha da escola dentro do sistema. Mas a idéia é justamente outra, a de poder produzir uma diferença, um estranhamento das práticas educativas usuais.

André: Penso que a rede poderia dar lugar a muitas experiências interessantes de sociabilidade, de criação de coletivos com interesses de aprendizagem e criação, que não fossem, digamos assim, experiências já demarcadas pelas experiências da escola tradicional. Quando as pessoas pensam em ensino a distância ainda o fazem de forma muito marcada pelas formas tradicionais de escola. É impressionante como as pessoas usam o ensino a distância mas não conseguem, nem mesmo produzir um conteúdo reticular, quanto mais uma transversalidade ao nível dos saberes.

Cleci: Temos tentado algumas experiências nesse sentido no Pós-Graduação em Informática na Educação na UFRGS. Sem dúvida o maior desafio é essa des-aprendizagem dos modos disciplinares da escola. André: para fazer isso é necessário um esforço, não é uma coisa que já é dada pela tecnologia...

Cleci: Realmente não.

André: Geralmente as pessoas pensam que basta usar uma nova tecnologia para produzir o novo. Mas não dá para fazer economia do esforço, da invenção, da experimentação. Na arte isso acontece de uma forma ainda mais complicada. A pessoa pensa que o fato de estar fazendo arte produz uma garantia do ponto de vista da criação, da invenção, se engana redondamente.

Cleci: Agradeço ao André pela entrevista e à Virgínia, a companhia nesse encontro. 